\title{
The Usage Characteristics of Twitter in the Learning Process
}

\author{
Anat Cohen and Galit Duchan \\ Tel Aviv University, Tel Aviv, Israel \\ anatco@post.tau.ac.il galitdu@gmail.com
}

\begin{abstract}
This research discusses the use of Twitter as a teaching-supporting tool in face to face (F2F) learning. The uniqueness and importance of this research is in the age group on which it focuses, an age group that has not yet been examined (ninth grade); furthermore, data was analyzed by decoding tweets, grouping tweets into various pedagogical and social uses, and exploring the technical difficulties that arise as a result of using Twitter. In addition, several communication characteristics that have not yet been analyzed regarding Twitter as an educational tool are included in the research. The results clearly show that both the students and the teacher used the new learning space mainly for pedagogical uses, as answers to homework questions and as comments to intriguing issues brought up throughout the lessons. The use of Twitter to support learning organization skills indeed assisted in avoiding time consuming difficulties in F2F learning. Analysis of all tweets during the research period has revealed valuable content. In spite of the fact that tweets were limited to 140 letters, from this study it was found that Twitter is an effective learning tool.
\end{abstract}

Keywords: Twitter, Collaborative learning, Web 2.0, Social networks.

\section{Introduction}

Information and Communication Technologies (ICT) available today enable educators, more than ever, to extend learning processes through a variety of tools, called Web 2.0 tools. These tools allow the use of the internet not only as a repository for information but as a means for creating, sharing and consuming information and knowledge. Many studies indicate the potential educational advancement which is inherent in a combination of tools such as Wiki, Blog, and Podcast for creation of collaborative knowledge in the teaching and learning processes (Clark, Logan, Mee, \& Oliver, 2009; Zang, 2009). Prensky (2008) emphasized that the challenge is not only diversification and enrichment of teaching by visual and demonstrative means that increase motivation among the students, but a combination of tools that allow students to actively participate in

Material published as part of this publication, either on-line or in print, is copyrighted by the Informing Science Institute. Permission to make digital or paper copy of part or all of these works for personal or classroom use is granted without fee provided that the copies are not made or distributed for profit or commercial advantage AND that copies 1) bear this notice in full and 2) give the full citation on the first page. It is permissible to abstract these works so long as credit is given. To copy in all other cases or to republish or to post on a server or to redistribute to lists requires specific permission and payment of a fee. Contact Publisher@InformingScience.org to request redistribution permission. the use of means for learning management and mentoring in order to facilitate the teacher in producing products and sharing them with the learning community.

Twitter is one of the Web 2.0 tools, which allows for the sharing of messages. Twitter users are able to post direct and indirect updates. Direct posts (personal messages) are used when a 
user aims her update to a specific person, whereas indirect updates (public messages) are used when the update is meant for anyone that cares to read it. Even though direct updates are used to communicate directly with a specific person, they are public and anyone can see them. Often times two or more users will have conversations by posting updates directed to each other (Huberman, Romero, \& Wu, 2008). The Twitter community is divided into Followers - the participants who choose to follow someone or a group- and Following - the user that you choose to follow and read his or her messages. The uniqueness of Twitter - the micro blogging and social networking platform most amenable to ongoing, public dialogue - is expressed in the combination of four characteristics: the length of message is limited to 140 characters and is called a tweet; the message is public, because reading it is not conditional upon author approval; the distribution of the message depends on the interest aroused among a group of followers; and the message transmission can be synchronous or asynchronous through mobile devices or stationary computers (O`Reilly \& Milstein, 2009).

This study deals with the potential of Twitter as a teaching-supporting tool in face to face (F2F) learning. During the research, short text messaging, including media files, was tested and determined to assist not only the personal-business, but also to create a leap in pedagogicalmanagement learning. The study examines how and to what extent the teacher and the students utilize the proposed technology to answer educational questions and for information sharing (pedagogical use); as support and encouragement for group members (the followers); and for the transfer of memorandums and messages (management use). In addition, this study examines the technical difficulties in implementing this new technology in a learning environment.

The uniqueness and importance of this research is in the age group on which it focuses, an age group that has not yet been examined (aged 14-15 - ninth grade, $\mathrm{N}=20$ ); furthermore, data was analyzed by decoding tweets, grouping tweets into various pedagogical and social uses, and exploring the technical difficulties that arise as a result of using Twitter. In addition, several communication characteristics that have not yet been analyzed regarding Twitter as an educational tool are included in the research.

\section{Background}

Web 2.0 is both a platform on which innovative technologies have been built and a space where users are as important as the content they upload and share with others. Web 2.0 includes social networks, such as MySpace and Facebook; media sharing, such as YouTube and Flickr; social bookmarking, such as Delicious; collaborative knowledge development through wikis (e.g., Wikipedia); creative works, such as podcasts, videocasts, blogs, and microblogs (e.g., Twitter, Blogger); content aggregation and organization, such as RSS (Really Simple Syndication) feeds and tagging tools; and remixing or mash-ups of content from different content providers into new forms, such as combining geographical data with transportation or crime data (Greenhow, Robelia, \& Hughes, 2009; Lankshear \& Knobel, 2007; O`Reilly, 2005).

Web 2.0 tools have potential to promote and improve educational processes. Alongside the development of the social learning community, diversification and enrichment of teaching by means of demonstration that increase motivation among students, there is also the challenge in using tools that allow students to be active (Clark et al., 2009; Greenhow et al., 2009; Prensky, 2008; Zhang, 2009). Twitter is one of the Web 2.0 tools that is considered to be a microblog. Similar to blogging, Twitter is a real-time network that allows users from across the globe to share information through private and public messages capped at 140 characters. The site-imposed character limit allows users' updates, or tweets, to be sent to cellular phones and other mobile devices as text messages (Waters \& Jamal, 2011). Consequently, the short messages of Twitter bring to mind the daily use of SMS (Short Message Service) with the mobile telephone (160 characters). Launched in the fall of 2006, Twitter has grown rapidly in popularity in recent years (Honeycutt 
\& Herring, 2009). According to data which was published in eBizMBA (the eBusiness Knowledgebase), Twitter was rated as the second most popular social networking site after Facebook, as of May 2012, with an estimated 250 million unique monthly visitors.

Various research groups around the world have begun to discover the magic of twittering, trying to harness twitter as a tool that supports the learning process. Twitter is a platform for sharing different types of media files along with short and concise text, which may contribute to interaction in the classroom and may improve instruction and learning possesses. At Sheffield Hallam University, England, fifteen students were asked to tweet 3 times per day about their learning routines and their physical location during their learning. Student's reflection shows that the daily report raises awareness and self-discipline for the learning process, and even enables collaboration with learners, who are in close proximity to their region (Aspden \& Thorpe, 2009). Junco, Heibergert, \& Loken (2010) from USA universities claim that analyses of Twitter communications showed that students and faculty were both highly engaged in the learning process in ways that transcended traditional classroom activities. Their study provides experimental evidence that Twitter can be used as an educational tool to help engage students and to mobilize faculty into a more active and participatory role. Furthermore, they show that using Twitter not only increases involvement and motivation for learning, but also contributes to improving educational achievement among experiment group participants, compared with the control group.

Dunlap \& Lowenthal (2009) used Twitter as an informal communication tool among students mainly for informal social purposes, in parallel to a Learning Management System (LMS) that accompanied the course. They argue that there is a need for a less cumbersome tool than the formal site that allows for free sharing of learning experiences. While their initial goal was to increase the socialization processes among learners, they actually received the following added values: better treatment in diverse problems and questions that were raised by the students in a concise and focused way due to the limit of 140 characters per tweet; connection with the professional community of the specific field concerning the learning content, supporting the formal learning process; and the creation of a community network which continued after the course as well. Wright (2010) also reported that there is an increased sense of belonging and community while working with Twitter. In his study he observed a group of teacher's certificate students, who have used Twitter as a tool for sharing in the practical experience. In Romania, a research team opened a microblog named Cirip.ro for a group of 40 participants, which includes students, teachers, developers and librarians. The course instructors guided the followers (the participants) through tasks, using a variety of Web 2.0 tools. After 1,100 posts were accumulated in the cloud they also reached the conclusion that Twitter is a potential tool for managing learning, with the recommendation that it should be limited to short-term activities because of its intensity. In addition they argue that improvements are required in the tagging of and the classification of posts (Holotescu \& Grosseck, 2009).

Studies show that there is potential in using Twitter for increasing teacher-student and studentstudent dialogue (Jansen, Zhang, Sobel, \& Chowdury, 2009; Kop, 2011). Learner involvement in the learning process, sharing materials and resources or difficulties in the learning process, and providing ongoing feedback that contributes to the sense of belonging to the learning community may lead to improvements in achievement. Unlike most of the studies which described asynchronous usage of Twitter, Rankin (2009), Professor of History at the University of Texas, assembled her ninety students every Friday for a synchronous discussion on course themes. Professor Rankin offered a working model with Twitter, which allowed for most students to share in the discussion. Utilization of this communication channel for learning management at administrative, social, and cognitive levels is still in its infancy and most of the reports provide only specific recommendations. The lack of use of Twitter by educators could possibly be the result of reluctance due to the 140 character limit per tweet, the difficulty in monitoring the intensity of tweets which 
are not categorized logically, and/or because of the privacy setting in the discourse (Holotescu \& Grosseck, 2009; Wright, 2010).

In Israel, the usage of Twitter as a learning tool in school is not common. However, the general public uses Twitter for social and business use. People upload questions to their followers, offer support, give advice, express opinions, and present ideas publicly, freely, and without cost. The basic assumption in the research presented in this paper is that such uses may promote the learning process where the learner actively gathers information, and processes it while interacting with colleagues.

The challenge in the current study presented in this paper is the students' exposure to Twitter and the estimation of its advantages and disadvantages as a teaching tool. This study examines how and to what extent the teacher and the students utilize the proposed technology to answer educational questions and to share information (pedagogical use); to support and encourage group members (the followers); and to transfer memorandums and messages (management use). In addition, this study examines the technical difficulties in implementing this new technology in a learning environment.

\section{Methodology}

\section{The Research Questions}

What kinds of uses for Twitter are taking place in the teaching and learning process? To what extent does technical difficulty manifest in using Twitter? And what are the communication characteristics of Twitter during the learning processes?

\section{The Study}

The study presented in this paper is a preliminary qualitative study. The population included twenty ninth grade students (aged 14-15), eleven girls and nine boys at a six-year school in the center of the country. This was a convenience sample from a study group of 38 students. The communication through Twitter was presented as a free choice in addition to a face to face biology class, held twice per week (three hours per week). The study included an exposure encounter with all class members $(\mathrm{N}=38)$, in which the versatile usage of Twitter throughout the world was introduced and demonstrated to the students, as well as the major functions of a Twitter group account. The students were asked to open a personal account on Twitter and follow the group and its members, including the teacher. Another guideline was to choose a name and/or a picture that would facilitate their identification on the network. The online discussion on Twitter took place over a period of 6 weeks, mostly asynchronous except for a few cases of random synchronous discussion.

\section{Research Tools}

A pre-experience questionnaire was designed and distributed to the students in order to supply a basic familiarity with the study population by checking their previous experience with Twitter and examining their ability to tweet from a mobile device. After the pedagogical activity using Twitter, a post-experience questionnaire was distributed asking the students to look at the sequence of the tweets and assess their contributions to the learning process, the dialogue expansion among themselves and with the teacher, and the sense of belonging to the group. In this phase the students who opened an account on Twitter, but did not actively participate, were asked to share their attitudes on the proposed tool as well.

Due to the lack of unique content analysis framework for twittering in Twitter, the collected data were classified into categories according to the "role analysis" of Berge (1995). Each tweet was 
cataloged in the following categories: pedagogical usage, social usage, organizational usage, and technical difficulties. In cases where a tweet fit multiple categories, it was categorized by the most dominant topic content of the post. Reliability of the coding was tested by agreement of two independent judges. Some examples of the coding are presented in Table 1.

Table 1: Examples of content analysis of posts on Twitter

\begin{tabular}{|c|c|c|}
\hline CATEGORIES & DATE & EXAMPLES OF TWITTER DISCOURSE \\
\hline \multirow[t]{3}{*}{$\begin{array}{l}\text { Pedagogical Usage } \\
\text { (raising questions, answers, } \\
\text { sharing materials) }\end{array}$} & 16.3 .11 & $\begin{array}{l}<\text { Teacher }>\text { "Here's something nice from the lesson today. All } \\
\text { white parts were dismantled by the enzyme amylase. All parts } \\
\text { painted in black (reacted with KI) are starch (amylum)..." }\end{array}$ \\
\hline & 26.3 .11 & $\begin{array}{l}<\text { teacher }>\text { addressing the group, regarding to assignment } 3 \text { : } \\
\text { "Activity of the stomach has been studied by a glimpse of a } \\
\text { hole in an Indian's stomach made by a bullet. } \\
\text { Would such an experiment be approved today? Find in Wiki: } \\
\text { human trials. } \\
\text { Share the arguments for and against it." }\end{array}$ \\
\hline & 29.3 .11 & $\begin{array}{l}<\mathrm{S}>\text { addressing a question to the group: } \\
\text { "Yesterday we heard on the news that someone's liver was } \\
\text { damaged from taking Nurofen continuously for five days. How } \\
\text { is it possible that the drug damaged their liver? Only acids exit } \\
\text { the liver to the stomach." }\end{array}$ \\
\hline \multirow[t]{3}{*}{$\begin{array}{l}\text { Social Usage } \\
\text { (support, encouragement, } \\
\text { group experiences) }\end{array}$} & 9.3 .11 & $\begin{array}{l}<\text { Teacher> addressing the group: } \\
\text { "Great to see that you are helping each other nicely. } \\
\text { You are welcome to share and help with materials and ideas } \\
\text { beyond specific assignments." }\end{array}$ \\
\hline & 10.3 .11 & $\begin{array}{l}<\text { Teacher> addressing the group: } \\
\text { "In preparation for the lesson about the digestive tract, share } \\
\text { with us what you like most to eat? And what will you not eat } \\
\text { even if your life depended on it?" }\end{array}$ \\
\hline & 7.4 .11 & $\begin{array}{l}<\mathrm{H}>\text { addressing the group: } \\
\text { "I wish you all an enjoyable Passover vacation: happy holiday } \\
\text { to everyone-(:." }\end{array}$ \\
\hline $\begin{array}{l}\text { Management Usage } \\
\text { (learning management, } \\
\text { notifications and remind- } \\
\text { ers) }\end{array}$ & 10.3 .11 & $\begin{array}{l}<\text { Teacher }> \\
\text { "My ninth grade class, welcome to the twittering class. Open an } \\
\text { account and join our 'Twitosphere'." }\end{array}$ \\
\hline
\end{tabular}




\begin{tabular}{|c|c|c|}
\hline & 16.3 .11 & $\begin{array}{l}<\text { Teacher }> \\
\text { "I am attaching a link to the circle of nutrition published by } \\
\text { CET (Center for Educational Technology) for a preparatory } \\
\text { work on the digestive system." }\end{array}$ \\
\hline & 1.3 .11 & $\begin{array}{l}<\mathrm{A}>\text { addressing the teacher: } \\
\text { "Galit, can I submit the assignment this Wednesday instead of } \\
\text { next Wednesday? Because I will not be in school on Wednes- } \\
\text { day and Monday." }\end{array}$ \\
\hline & 3.4 .11 & $\begin{array}{l}<\text { Teacher }> \\
\text { "Hey everyone, I have entered the 'smart school' (grade system) } \\
\text { grades for your beautiful work, which you submitted on diges- } \\
\text { tion. It will be distributed in class tomorrow." }\end{array}$ \\
\hline & 3.5 .11 & $\begin{array}{l}<\mathrm{S}>\text { Addressing the group: } \\
\text { "I have a question. In order to study for the test on digestion, is } \\
\text { it enough to read the work we have done and the paper with the } \\
\text { table, which we did in class? I didn't find other material." }\end{array}$ \\
\hline \multirow[t]{3}{*}{ Technical Usage } & 16.3 .11 & $\begin{array}{l}<\mathrm{P}>\text { Opened the account and tweet: } \\
\text { "I still don't understand how to use it..." }\end{array}$ \\
\hline & 26.3 .11 & $\begin{array}{l}<\mathrm{S}>\text { Notify the group: } \\
\text { "There is a strange looking plant that I have photographed. But } \\
\text { I don't know how to upload the picture here, help?" }\end{array}$ \\
\hline & $\begin{array}{l}9.4 .11 \\
11.4 .11\end{array}$ & $\begin{array}{l}<\mathrm{D}>\text { Sent the teacher a private message instead of public mes- } \\
\text { sage, in which he writes the technical difficulty. } \\
<\text { Teacher }>\text { "Did you notice that you have sent a private Tweet } \\
\text { and not a public one?" } \\
<\text { D }>\text { "I don't know the other way to send it. This is the only } \\
\text { way I know". } \\
<\text { Teacher }>\text { "Look for the icon on the right side next to your } \\
\text { name. It is a square with a pen in it. Clicking it will open a } \\
\text { 'What's up?' window where you can type a tweet. Or, you can } \\
\text { create a new comment, or click on Reply." }\end{array}$ \\
\hline
\end{tabular}

Following an examination of a variety tools of analysis (such as tools which appear on the websites http://tweetstats.com, http://twittercounter.com, http://flockchart.com/), it was decided to use the "tweetstats" tool. The tweets were documented by dates and participants, which made it easier for data mining and processing. Additionally, it was decided to use the "Wordle" tool for generating the "Word Cloud" from all tweets (teacher and students tweets).

\section{Findings}

Processing the preliminary questionnaire revealed that only three students out of the total class (38 students) had previous exposure to Twitter. All three are included in the sample $(\mathrm{N}=20)$. During six weeks of research, 143 tweets were produced in the "Twitosphere". Following are the findings concerning the use of Twitter during this research with regard to types of usage and communication characteristics of this tool. 


\section{Usage Classification in Twitter in Teaching and Learning Processes}

The examination of usage was made, as stated, by encoding the tweets (of the teacher and her students) to pedagogical, social, management, and technical uses. The results show that nearly half of the tweets (48\%) dealt with pedagogical issues, including questions clarifying homework, references to experiment results, ideas raised in class, and questions about topics tangential to the lesson (gastric surgery, swimmers nutrition, the phenomenon of eye color Heterochromia, etc.). Social support, including feedback and encouraging words, and reference to the opening task which aimed to encourage socialization, constituted approximately $27 \%$ of tweets. Twenty percent of the tweets were messages, including reference to the learning management such as coordinating schedules for submission of assignments, class dates, resources for preparing assignments, notices about grades and announcements regarding test material. The Twitter followers also updated the rest of the students in the class with information which saved precious time in the classroom lesson. A relatively small percentage of tweets $(5 \%)$ were messages indicating difficulty in operating the tool, for example uploading images (Figure 1).

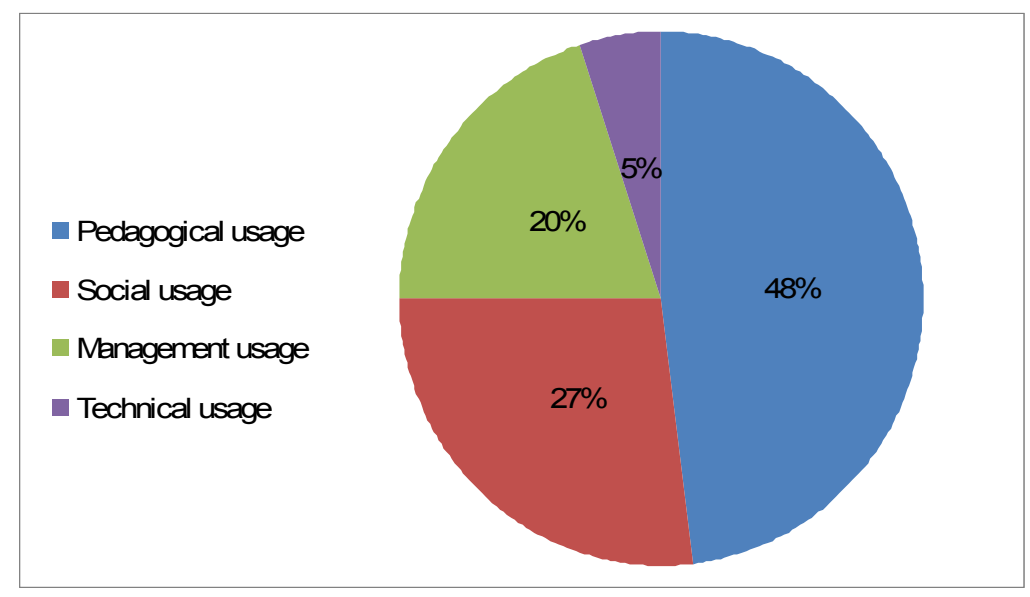

Figure 1: Rate of the teacher and students tweets on Twitter, classified by type of use.

When comparing the usage in instructional processes (teacher tweets) and the usage in the learning processes (student tweets) a significant difference can be seen in two dimensions: the social and the organizational dimensions. It is apparent that in these categories the students used Twitter more than the teacher: in the social usage category $69 \%$ were student tweets while $31 \%$ were teacher tweets. In the management usage category $64 \%$ were students tweets compared with $36 \%$ by the teacher (Table 2 ).

Table 2: Distribution of teacher tweet types compared to distribution of student tweet types in Twitter

\begin{tabular}{|l|l|l|l|l|l|l|}
\hline CATEGORY & $\begin{array}{c}\text { NO. OF } \\
\text { TWEETS } \\
\text { (TEACHER + } \\
\text { STUDENTS) }\end{array}$ & $\begin{array}{c}\text { \% OF TWEETS } \\
\text { (TEACHER + }\end{array}$ & $\begin{array}{c}\text { NO. OF } \\
\text { TEACHER } \\
\text { TWEETS }\end{array}$ & $\begin{array}{c}\text { \% OF } \\
\text { TEACHER } \\
\text { TWEETS }\end{array}$ & $\begin{array}{c}\text { NO. OF } \\
\text { STU- } \\
\text { DENTS } \\
\text { TWEETS }\end{array}$ & $\begin{array}{c}\text { \%F STU- } \\
\text { DENTS } \\
\text { TWEETS }\end{array}$ \\
\hline Pedagogical & 69 & 48 & 36 & 52 & 33 & 48 \\
\hline Social & 39 & 27 & 12 & 31 & 27 & 69 \\
\hline Management & 28 & 20 & 10 & 36 & 18 & 64 \\
\hline Technical & 7 & 5 & 4 & 57 & 3 & 43 \\
\hline Total & $\mathbf{N}=\mathbf{1 4 3}$ & & $\mathbf{N}=\mathbf{6 2}$ & & $\mathbf{N = 8 1}$ & \\
\hline
\end{tabular}


Word Cloud is another web-2.0 tool that indicates the nature of the discourse on Twitter. The cloud displays the most prevalent words used in the discourse; the largest words being the most widely used. This Word Cloud was produced using data from the research group's Twitosphere (all teacher and students tweets during the discourse) and was created using the site http://www.wordle.net/create as shown in Figure 2.

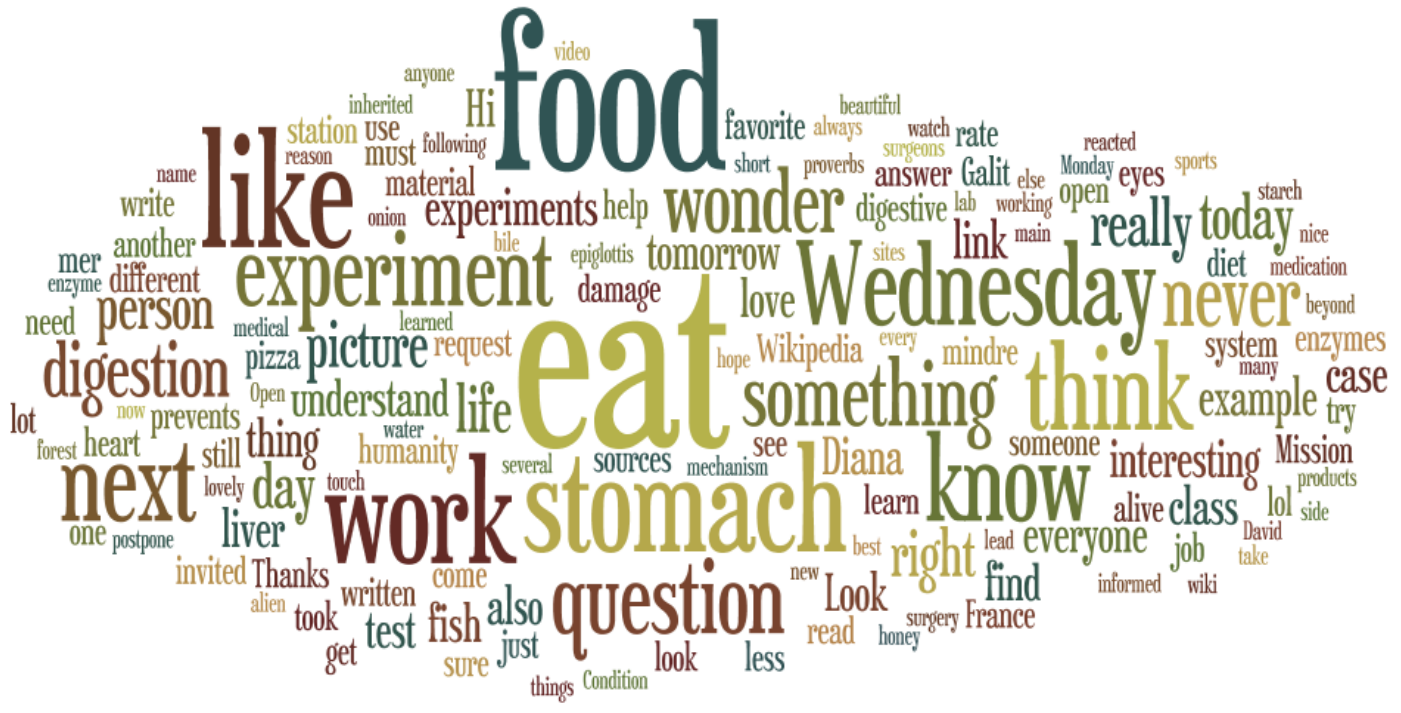

Figure 2: Twitosphere Word Cloud

The Word Cloud gives us a glimpse into the follower's diverse usage of Twitter. Words in this Word Cloud display the usage results of the research in a parallel manner to Figure 1, in that the larger words represent the Pedagogical and Social Usage categories. Although prevalent words are displayed, they are out of context and impossible to categorize. One must be familiar with the specifics of the study, i.e., a biology class held on Wednesday where digestion and other topics were studied.

\section{Communication Characteristics in the Learning Processes on Twitter}

The following findings are based on data which was collected through tweet documentation combined with student responses from the post-experience questionnaire. An interaction was defined as a tweet between two or more people, while two main interactions were discerned. The first was interaction between the teacher and students (teacher-student interaction), meaning twittering by the teacher to the entire group or to one student in the group publicly. The second was interaction between two students (student-student interaction), meaning a public tweet (not a private message) among the group members without the mediation of the teacher. The data showed that $92 \%$ of the interactions were group interactions between the teacher and the students and only a minority $(8 \%)$ was communication among students without teacher mediation.

Private interaction (sending a private message) is another type of interaction that is possible in twitter where a direct message is sent to one of the followers. It is also possible to cite one of the group followers' messages or one of the all twitter messages in the network and share it with the group. This is referred to as a Retweet (RT). In this study RTs were not found and personal messages among the students were not counted. 


\section{Degree of Learner Activity When Using Twitter}

Learner activity in this study was examined by the number of times in which the students twittered on Twitter as a measure of participation. Another measure of learner activity was derived from observing the content which they initiated and raised for discussion. The findings show that 143 tweets were posted. Of the total tweets, 81 were posted by the twenty students who participated, meaning that $57 \%$ of the tweets during the study were student tweets. But after looking at the content, it was discovered that only a small portion of the tweets (approximately 6\%) express initiative by five students to raise a topic for discussion and/or to share media from an image or movie.

\section{Learner Participation on Twitter}

Learner participation was examined in terms of gender and group dynamics. No gender differences were found in the participation rate in online discourse on Twitter. The boys $(\mathrm{N}=9)$ posted 39 tweets ( $48 \%$ of all student tweets). The girls $(\mathrm{N}=11)$ posted 42 tweets $(52 \%$ of all student tweets). Group dynamics were examined by analyzing the number of tweets for each student listed in the followers group (Table 3).

Table 3: Frequency of student (followers) tweets on Twitter

\begin{tabular}{|l|l|l|l|l|}
\hline $\begin{array}{c}\text { NO. OF } \\
\text { TWEETS PER } \\
\text { STUDENT (X) }\end{array}$ & $\begin{array}{c}\text { FREQUENCY } \\
\text { (F) }\end{array}$ & $\begin{array}{c}\text { FREQUENCY } \\
(\%)\end{array}$ & $\begin{array}{c}\text { CUMULATIVE } \\
\text { FREQUENCY } \\
\text { (CF) }\end{array}$ & $\begin{array}{c}\text { CUMULATIVE } \\
\text { FREQUENCY } \\
\text { (CF\%) }\end{array}$ \\
\hline 0 & 3 & 15 & 3 & 15 \\
\hline 1 & 1 & 5 & 4 & 20 \\
\hline 2 & 3 & 15 & 7 & 35 \\
\hline 3 & 3 & 15 & 10 & 50 \\
\hline 4 & 2 & 10 & 12 & 60 \\
\hline 5 & 3 & 15 & 15 & 75 \\
\hline 6 & 1 & 5 & 16 & 80 \\
\hline 7 & 1 & 5 & 17 & 85 \\
\hline 11 & 2 & 10 & 19 & 95 \\
\hline 15 & 1 & 5 & 20 & 100 \\
\hline & $\mathbf{N}=\mathbf{2 0}$ & $\mathbf{1 0 0}$ & & \\
\hline
\end{tabular}

Examining the frequency of the learner (followers) tweets (Table 3) reveal that the distribution is asymmetrical and abnormal with a large variance. Consequently, it would be incorrect to relate to the average (5.4 with a standard deviation of 2.41), and the Inter-Quartile Range (IQR) should be used. The calculation of the IQR indicates that $50 \%$ of the learners tweeted between $2-5$ tweets during the study. In the post-experience questionnaire $50 \%$ of the learners stated that they checked Twitter once per day, 20\% said that they checked Twitter twice per day, while $30 \%$ said that even though they opened an account, they did not use it (although in practice only three out of six did not tweet at all). Theoretically, there is no limit to participation in the online Twitter group and every learner has the equal opportunity to post a media item, a topic for discussion, or to comment. Therefore, it was interesting to examine the explanations of the six out of twenty students who opened Twitter accounts but claimed that they did not take an active part in the followers group for various reasons. The following are their explanations as they appeared in the post-experience questionnaire: "First of all, I didn't know how to use it, and I had no desire"; "It didn't interest me!"; "When I was at home, I didn't think about Twitter. I have limited 'computer time' and I wanted to use it for other things"; "I was not interested in tweeting"; "I generally only watch the dialogues that take place on Twitter, rather than writing comments. If there was anything important to add, I probably would have"; "I do not like to participate." 


\section{Learner Activity Time on Twitter}

With regard to learner activity distribution on Twitter, it is feasible to observe the activity hours throughout the day for all followers: teacher and students (Table 4) and to be impressed by the number of teacher tweets each day of the week (Figure 3). This data was extracted by using the site: http://tweetstats.com (for reasons of group member privacy, the full path of the URL was not provided because it contains the name of the group).

\section{Figure 3: Daily frequency of teacher tweets on Twitter}

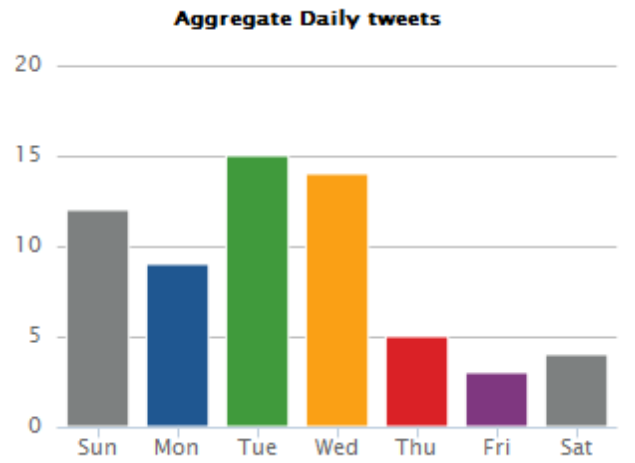

Table 4: Distribution of Twitter usage for all followers (teacher and students) throughout the day in percentages

\begin{tabular}{|l|l|l|l|}
\hline \multicolumn{1}{|c|}{ TIME } & \multicolumn{1}{c|}{ HOURS } & $\begin{array}{c}\text { NO. OF } \\
\text { TWEETS }\end{array}$ & \multicolumn{1}{c|}{$\%$} \\
\hline Night & $0-3.59$ & 5 & $4 \%$ \\
\hline Before dawn & $4-7.59$ & 1 & $1 \%$ \\
\hline Morning & $8-11.59$ & 9 & $6 \%$ \\
\hline Noon & $12-15.59$ & 19 & $13 \%$ \\
\hline Afternoon & $16-19.59$ & 40 & $28 \%$ \\
\hline Evening & $20-23.59$ & 69 & $48 \%$ \\
\hline & & $\mathbf{N}=\mathbf{1 4 3}$ & $\mathbf{1 0 0} \%$ \\
\hline
\end{tabular}

The results show that for the six weeks during which the research was conducted, 35 days were counted in which at least one tweet by the teacher or a student was recorded. Most activity was in March while on the $27^{\text {th }}$ and $29^{\text {th }}$, a record number of 25 and 28 tweets were counted correspondingly. Most tweets (76\%) were sent to the "Twitosphere" between the hours of 16:00 to 23:59. Approximately $20 \%$ of the tweets were posted during school time between 8:00 to 15:59, and only $4 \%$ of the tweets were posted late at night and in the morning (four of them were posted by the teacher). Figure 2 shows that the teacher tweets were mainly posted between Sunday and Wednesday.

In this study there was no synchronous use of Twitter with the entire class (38 students) due to time constraints and small sample considerations $(\mathrm{N}=20)$. However, a number of teacher-student and student-student synchronous discussions occurred randomly in the afternoon and late evening, without teacher initiative or intervention.

\section{Effect of Message Length Limitation on Interaction between Learners on Twitter}

In the tweet sequence only one reference was found regarding the difficulty to express the message in 140 characters. The follower tweet to the group: "This message is a continuance from the previous. I just had no place ..."

In the post-experience questionnaire, when they were asked about the Twitter disadvantage, only three students referred to this issue of the length limitation of the message as a limiting factor in the interaction. For example: "The disadvantage of using Twitter is the limited message length, sometimes you cannot type all that you want to in one message. It does cause one to think about how to save words, but sometimes it's really annoying". 


\section{Discussion}

This research shows a Twitter experience with a group of ninth graders and found that the students and the teacher used Twitter to their advantage, as a learning space for answering questions and uploading information (for educational use).

Twitter allows multi-directional dialogue and free discussion as opposed to the discussion in the classroom, which requires speech by request. The data showed that there were various free interactions, however most posts were made to the teacher. This finding is a reminder of the class dynamic, which was pointed out by Blum-Kulka \& Vardi-Rath (2005), though here this was the student's choice and not a result of a teacher's formal guidance. It could be derived from a technical convenience in the initial use of Twitter, or perhaps this may be the result of habit and a student's expectation to get help and feedback from the authority figure.

Interaction on Twitter allows for the assessment of difficulties encountered by students on a particular topic; to find students who do not participate in class and to enable more introverted students to express themselves freely on the network; and to help others to learn about their interests, places, and phenomena they encountered that aroused their curiosity. The Twitter interactions relating to the Heterochromia topic illustrate the fact that the teacher does not own the knowledge exclusively and that the students can learn from each other.

In the pre-experience questionnaire, most students stated that they occasionally feel they have ideas, images, and videos related to the subject matter and they would like to share them with the rest of the students. In practice, most of the students were twittering, but few initiated and shared details with the followers. This finding can be attributed to lack of experience, to personal preferences arising from the nature of the learner, to study load and the need to redirect time for other things, and to difficulties in acclimating to Twitter usage resulting in the avoidance of sharing. Nevertheless, there is potential for spreading information collected by students in a serendipitous way, interpreting it, and relating it to curricular knowledge, thereby empowering the learner and enhancing the learning experience by making it more relevant to the learner, as proposed by Toffler (1972) and Salomon (2001).

Twitter enables communication at any time and anywhere, creating the potential for learning beyond the classroom.

Using Twitter stemmed from a pedagogical-administrative need and not as a routine pattern. While $52 \%$ of the teacher tweets were from a stationary computer, $48 \%$ of them were from a mobile telephone. In contrast, only $20 \%$ of students reported that they post from a mobile device. There is a possibility that an increase in smart mobile devices among students may change the amount of Twitter use and raise the opportunities for synchronous discourse (Goad, 2012; Wright, 2010).

One of the main factors that deters educators from using Twitter as a learning tool is the limit of 140 characters per tweet. It is perceived that 140 characters is too small a space for any meaningful information to be exchanged, but Twitter users have found creative ways to get the most out of each tweet by using different communication tools (Boyd, Golder, \& Lotan, 2010; Lovejoy, Waters, \& Saxton, 2012). During this study the sequence tweets raise significant and often surprising content, even in the absence of the writing options available in tools such as a blog or educational forum.

It has been determined that Twitter is an effective tool for posting short questions, messages, coordination collaboration, emotions, and also for sharing information such as a reference to a book or an article that the group was asked to read. Professor Rankin (2009) encouraged history students to write several subsequent tweets to overcome the difficulty of expressing an idea in 140 characters. The summary requires the user to refine the message, but may also lead to liable dis- 
ruption (Holotescu \& Grosseck, 2008). Examining twitter log files proves that students maintain wording clearly and satisfactory.

Zhang (2009) argued that sometimes a collaborative medium (not just Twitter) is superficial because the ideas that arise in the group do not receive a thorough process and there is no continuity and commitment to the process which is the basis for creating knowledge. An example is the discussion that occurs in this study on Twitter about "Pros and cons of human experiments". The discussion did not receive broad and profound attention, but there is a possibility that the reason lies in the fact that the topic came up in class during a F2F lesson and it was not part of the curriculum. In the words of one of the students "... all the students did not participate because it was at the expense of their free time, and they did not think about this during the day because it was not an obligation". The potential in raising the topic on Twitter is a flooding of issues and ideas, which arose while clarifying the argument and sharing it through online media, available to all at anytime and anywhere from different devices. This is a trigger for further in-depth discussion in the plenum using arguments and materials from the tweets. That is to say, the depth of the discussion is not derived from the number of words in the text but from the content of the subject matter, the motivation, and the rhetorical skill. It is a challenge for the teacher to stimulate students to seek answers to fruitful questions and to stimulate dialogue among the students on Twitter.

\section{Conclusions}

This preliminary study supports the claim that the challenge in Web 2.0 tools such as Wiki, Blog, and Twitter, is not only diversification and enrichment of teaching by means of demonstration that increase motivation among students, but allowing students to be active (Prensky, 2008). There is an educational potential in these tools to create collaborative knowledge in teaching and learning processes (Clark et al., 2009; Zang, 2009), to develop social relations in learning communities (Clark et al., 2009; Greenhow et al., 2009; Zhang, 2009), and to adjust schools to the social changes which are taking place in the 21 st century, as mentioned by Dede (2005).

In this study Twitter was found to be a teaching-supporting tool in face to face (F2F) learning. While the use of Twitter to organize learning came naturally and did not require any special attention, the pedagogical use does require advanced planning for guiding the group. Pedagogical use can be encouraged by raising open questions which stimulate discussion while guiding students to respond to their colleagues' tweets. Furthermore, combining knowledge experts from the community (teachers / parents) may enrich the discourse and demonstrate the authenticity of the learning subjects to the students.

The teacher presence with professional online identity allows him or her not only to provide information on wise use of the web and social networks, but to build together norms skills of the 21 st century. This is reflected in combined range of Web 2.0 tools in the tweets (such as Wikipedia, YouTube, QRcode, etc.); in critical thinking about sources of information; in improving practice in brief message transmission, including text and media; and of course in providing of protected network model.

Using an online space for learning challenges the teacher in pedagogical, technological, and ethical aspects regarding publicity of the message, exposure to advertising, and blurring the boundaries between teacher and student. Even though the challenge is big and sometimes threatening, ignoring the networks and the academic potential might mistakenly bypass the opportunity to personally sample the online space which is multi-channel, authentic, and updated dynamically.

The choice of Twitter as a learning tool entails difficulties too. Some of them are related to the teacher and the learner, but others are related to diverse possibilities, which are integral to the technology itself. The sequence of Twitter posts appear in chronological order and not by topic, which makes it difficult for some students to adapt. In addition, the teacher may experience a 
sudden accumulation of public / personal tweets that require individual feedback, for which it is recommended to set aside specific periods of productive time in advance. Moreover, the integration of Twitter, like any new technology, requires attention to technical malfunctions such as a network collapse during synchronous tweeting, as well as differences among learners in implementing the technology. Distribution of training videos, F2F demonstration of the use of different functions (such as uploading a photo, RT, Hashtag, etc.), and appointing students as experts in order to assist other students may increase the success in implementing Twitter.

The findings of this study raise the need for further critical examination of methods for Twitter integration as well as other Web 2.0 tools into the school environment. There is a need to develop models that will help teachers and students integrate these tools in a meaningful way to their teaching and learning.

Due to a small sample, this preliminary study was not representative; however it can be seen as an exploratory focus on the use of Twitter as a teaching-supporting tool in F2F learning. The followup study is a phenomenological study which explores the experience of a large sample of students and teachers using Twitter for learning during the school year. Twitter will be analyzed as a teaching-enhancing tool, with a focus on insights to the characters of micro blogging that support ubiquitous micro learning.

It is hoped that this study will stimulate awareness and desire among teachers and researchers to further test its application. Twitter is one of the tools that can be seen as scaffolding in the learning process and may enable a skilled, creative, and motivated teacher to enhance the teaching process.

\section{References}

Aspden, E. J., \& Thorpe, L. P. (2009). Where do you learn? Tweeting to inform learning space development. Educause Magazine, 32(1).

Berge, Z. L. (1995). Facilitating computer conferencing recommendation from the field. Educational Technology, 35(1), 22-30.

Blum-Kulka, S., \& Vardi-Rath, E. (2005). The lesson as an asymmetric speech event - A look at Israeli classroom participation structure [Hebrew] Retrieved 13 May 2012, from http://portal.macam.ac.il/ArticlePage.aspx?id=901

Boyd, D., Golder, S., \& Lotan, G. (2010). Tweet, Tweet, Retweet: Conversational aspects of retweeting on Twitter. HICSS '10 Proceedings of the 2010 43rd Hawaii International Conference on System Sciences.

Clark, W., Logan, K., Luckin, R., Mee, A., \& Oliver, M. (2009). Beyond Web 2.0: Mapping the technology landscapes of young learners. Journal of Computer Assisted Learning, 25(1), 56-69.

Dede, C. (2005). Planning for "neomillennial" learning styles: Implications for investments in technology and faculty. In J. Oblinger \& D. Oblinger (Eds.), Educating the net generation (pp. 226-247). Boulder, CO: Educause Publishers.

Dunlap, J. C., \& Lowenthal, P. R. (2009). Tweeting the night away: Using twitter to enhance social presence. Journal of Information Systems Education, 20(2), 129-136.

eBizMBA - the eBusiness Knowledgebase. Retrieved May 9, 2012, from http://www.ebizmba.com/articles/social-networking-websites

Goad, K. D. (2012). The perception of teachers toward the use of mobile technology as a tool to engage students in learning. PhD dissertation. Department of Educational Leadership, Administration, and Foundations, Indiana State University. Retrieved August 25, 2012, from http://hdl.handle.net/10484/4004 
Greenhow, C., Robelia, B, \& Hughes, J. E. (2009). Web 2.0 and classroom research: What path should we take now? Educational Researcher, 38(4), 246-259.

Holotescu, C., \& Grosseck, G. (2009). Using micro blogging in education. Case study: Crip.ro. Paper presented at $6^{\text {th }}$ International Conference on e-learning Application, Cairo, Egypt.

Honeycutt, C., \& Herring, S. C. (2009). Beyond microblogging: Conversation and collaboration via Twitter. Proceedings of the forty-second Hawai'I international conference on system sciences (HICSS-42). Los Alamitos, CA: IEEE Press.

Huberman, B., Romero D., \& Wu, F. (2009). Social networks that matter: Twitter under the microscope. First Monday [Online], 14(1).

Jansen, B. J., Zhang, M., Sobel, K., \& Chowdury, A. (2009). Twitter power: Tweets as electronic word of mouth. Journal of the American Society for Information Science and Technology, 60, 2169-2188.

Junco, R., Heibergert G., \& Loken, E. (2010). The effect of twitter on college student engagement and grades. Journal of Computer Assisted Learning, 27(2), 119-133.

Kop, R. (2011). The challenges to connectivist learning on open online networks: Learning experiences during a massive open online course. International Review of Research in Open and Distance Learning, 12(3), 19-38.

Lankshear, C., \& Knobel, M. (2007). Researching new literacies: Web 2.0 practices and insider perspectives. E-Learning and Digital Media, 4(3), 224-240.

Lovejoy, K., Waters, R. D., \& Saxton, G. D. (2012). Engaging stakeholders through Twitter: How nonprofit organizations are getting more out of 140 characters or less. Public Relations Review, 38(2), 313-318.

O'Reilly, T. (2005). What is Web 2.0? Design patterns and business models for the next generation of software. O'Reilly. Retrieved May 9, 2012, from http://oreilly.com/web2/archive/what-is-web-20.html

O`Reilly, T., \& Milstein, S. (2009). The Twitter book. O'Reilly Media, Inc.

Prensky, M. (2008). The role of technology in teaching and classroom. Educational Technology, 48(6).

Rankin, M. (2009). Some general comments on the "Twitter Experiment". Retrieved May 9, 2012, from http://www.utdallas.edu/ mar046000/usweb/twitterconclusions.htm

Salomon, G. (2001). Technology and education in the age of information. Zmora-Bitan [Hebrew].

Toffler, A. (1972). Future shock. New York: Random House.

Waters, R. D., \& Jamal, J., Y. (2011). Tweet, tweet, tweet: A content analysis of nonprofit organizations' Twitter updates. Public Relations Review, 37, 321- 324.

Wright, N. (2010). Twittering in teacher education: Reflecting on practicum experiences. Open learning: The Journal of Open, Distance and e-Learning, 25(3), 256-265.

Zhang, J. (2009). Towards a creative social web for learners and teachers. Educational Researcher, 38(4), 274-279. 


\section{Biographies}

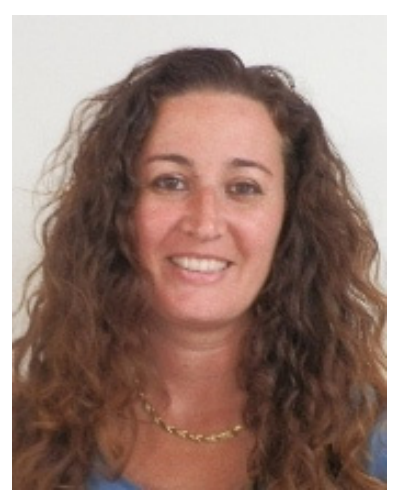

Anat Cohen is a researcher and a lecturer in Tel-Aviv University's School of Education. Her Ph.D dissertation analysed the costeffectiveness of Web-based Education, based on theoretical and computational models and empirical data using web-mining techniques. She participated in the IEA's Second International Technology in Education Study (SITES) and is currently a research and pedagogical coordinator of Virtual TAU - Web-Supported Academic Instruction in Tel-Aviv University. She has published over 40 research papers in leading peer-reviewed journals and conference proceedings. Her major research areas are: Cost-Effectiveness of Web-based Learning, Learning object repositories, Ubiquitous Learning, ICT implementation in Higher Education, Educational Data-Mining.

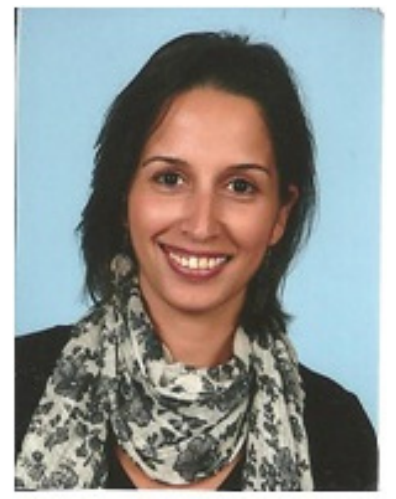

Galit Duchan is a Graduate student in Tel-Aviv University's School of Education, the Math, science, and technology education department. She is a Biology teacher for 14 years at middle and high school. Galit thesis is based on the study presented in this paper: "The usage characteristics of twitter in learning process" under the supervision of Prof. Rafi Nachmias and Dr. Anat Cohen. 